\title{
GIS Based Management System for Photovoltaic Panels
}

\author{
Muhammad Luqman1", Sajid Rashid Ahmad1, Samiullah Khan1, Farkhanda Akmal1, \\ Usman Ahmad', Ahmad Raza1, Muhammad Nawaz' ${ }^{2}$, Asif Javed ${ }^{3}$, Hamad Ali ${ }^{4}$ \\ ${ }^{1}$ Institute of Geology, University of the Punjab, Lahore, Pakistan \\ ${ }^{2}$ Department of Space Science, University of the Punjab, Lahore, Pakistan \\ ${ }^{3}$ Punjab Group of Colleges, Kasur, Pakistan \\ ${ }^{4}$ Punjab University College of Information Technology, University of the Punjab, Lahore, Pakistan \\ Email: ${ }^{*}$ m luqman1@yahoo.com
}

Received 11 June 2015; accepted 11 August 2015; published 14 August 2015

Copyright (C) 2015 by authors and Scientific Research Publishing Inc.

This work is licensed under the Creative Commons Attribution International License (CC BY). http://creativecommons.org/licenses/by/4.0/

(c) (i) Open Access

\section{Abstract}

This paper provides a proposal of implementation of latest technologies in photovoltaic installation and management system. Punjab Government Cooperative Housing Society was selected to find out suitability for photovoltaic installation and its management after that. Google Earth imagery and scanned maps were selected for the preparation of spatial and attribute data of buildings in the study area by using ArcGIS software. In first stage data were digitized and suitability and potential for each building were estimated. In second stage all the tabular data which consisted of owner information, panel information, its potential and location were linked to each other for management purpose. Selected area for solar panels installation was linked to building information for query and visualization.

\section{Keywords}

Photovoltaic (PV), Asset Management, Google Earth Imagery, ArcGIS 10, Geographical Information System (GIS)

\section{Introduction}

GIS is an information system or technology which has strong capability to maintain and analyze geographic or spatial data. Data stored in GIS program have geography as well as attribute information. GIS technology maintains the data into layers and relating sets by geography. GIS is more easily conveyed in geographic layout than

*Corresponding author.

How to cite this paper: Luqman, M., Ahmad, S.R., Khan, S., Akmal, F., Ahmad, U., Raza, A., Nawaz, M., Javed, A. and Ali, H. (2015) GIS Based Management System for Photovoltaic Panels. Journal of Geographic Information System, 7, $392-401$. 
traditional tabular formats [1]. GIS functionality may be presented in desktop, mobile or in internet browser [2]. Application of GIS is increasing day by day due to its predictive models which are providing functions for the data storage, manipulation, calculation, analysis and output processing [3]. GIS capabilities have been utilized to provide spatial data management system and spatial decision support system (SDSS) with output display [4]-[6].

In GIS applications, presentation of reality by using basic geometries of features, their accuracy, preparation and processing of data has different resources. Analysis is applied on data to get results [7] [8]. GIS has deep impacts on the public organizations which deal with utility networks like gas, water and power supply. GIS is not limited to utilities; it also deals with the management and planning of infrastructures easily [9]-[11]. Competition for the human technology is increasing in market; it becomes mandatory for the users and proprietors to be up to date by using latest technologies [12]. GIS is a system which consists of hardware, software, data and people capable to capture, store, update, manipulate, analyze and display spatial data (ESRI, 1990). GIS is a complete software package capable of complete database system. GIS has all functionalities of computer system which are required to make cartographic presentations and maps [13]. ESRI (1990) is enhancing and updating the database with the passage of time, to handle new datasets and spatial data with new procedures and techniques [14].

Electric energy short fall is very problematic issue in Pakistan at present era. Domestic and well as commercial users are facing the same problem. According to Pakistan Electric Power Company (PEPCO), the peak energy demand in June 2012 was 17,861 Mega Watt (MW) at the same while peak energy generation capacity of PEPCO (2012) was 14,317 MW [15]. It is clear that there is short fall of $3544 \mathrm{MW}$. Consumers have to face load shedding due to this energy shortfall and a fraction of them uses other sources of energy like electric generators, uninterrupted power supply, solar panels etc. Arifeen (2013) analyzed in his article in newspaper that electricity demand had increased by $80 \%$ in last 15 years in Pakistan [16]. Water and Power Development authority (WAPDA) estimated that electric energy demand by the consumer in the country would be 40,000 MW by 2020 in Pakistan. There was $4.8 \%$ increase in energy demand every year, but it was expected that, in the future, this demand would be $8 \%-10 \%$ per year; so $7 \%-8 \%$ rate of energy increase was necessary in the energy generation.

All the energy sources like hydro power, oil, gas, nuclear energy, solar energy etc. are being used to produce electricity in Pakistan. But the sources like oil and gas are expensive. The Government of Pakistan made an autonomous board in 2003 for the research and generation of electricity from renewable energy. The board is called Alternative Energy Development Board (AEDB). AEDB was assigned a task to find out the all means of renewable energy. The board has a task of 5\% share of total energy demand of electricity in the country by 2030 [17].

Solar radiations from sun have potential energy 6000 times the total energy demand of entire world [18]. Pakistan has a good geographic location for the reception of solar radiation as Pakistan has long shining hours and abundant amounts of irradiance. In Pakistan, it is estimated that there is 1.9 - 2.3 Mega Watt hour per meter square $\left(\mathrm{MWh} / \mathrm{m}^{2}\right)$ solar energy potential while at particular places like Cholistan and desert areas the amount raises from average [17]. At present there are only two projects which are working using solar energy. The first project is working in District Kasur by a private stakeholder Roshan Power Pvt. Limited and the second is in Cholistan owned by CWE \& WK (JV) producing $10 \mathrm{MW}$ and $50 \mathrm{MW}$ respectively. A solar power park project is under progress in Bahawalpur with proposed capacity of $100 \mathrm{MW}$ by December 2014 [19]. 27 LOIs have been issued for a consolidated capacity of 792.99 MW in Pakistan [20]. Solar energy is also being used in Pakistan in emergency phone both along the motorway and road light in Lahore etc.

\section{Research Proposal}

Government of Pakistan has announced a policy to purchase electric energy from stakeholders. Stakeholders may produce electric energy with the help of solar technology. According to policy, this energy would be added to national grid for domestic as well as commercial uses. As solar energy generation is a spatial related task i.e. solar energy is not the same at all geographic locations, geographic information system is proposed as management information system for the production and addition of generated energy in to national grid. For this purpose, a study is proposed for the installation of solar panels at the rooftops of households. Usually GIS is considered as a system for spatial analysis and decision support but in our study we propose GIS as a management information system in energy sector. 
Solar panels can easily be installed in any land. These lands may be barren lands, closed landfill sites, along the roads, in deserts, in agricultural land or on the roofs of the building. In this study residential buildings are selected so that there will be no loss of agricultural land and energy transmission loss. GIS database would have records for each house for energy generation. The energy generated by the roofs of the buildings would be added to national transmission grid. The energy production record for each building would be record in a database. Geographic information system has a SQL database in it. GIS has database for each house number, its size and selected roof area for panel installation, distance to national grid and energy generation from each building roof. Database management system is a software that collects, manipulates, queries and retrieves tabular data. In GIS, DBMS is related to each geographic feature as well. So GIS is a powerful software which maintains geographic as well as tabular data.

\section{Methodology}

\subsection{Study Area}

The Punjab Government Servants Housing Scheme (PGSHS) Lahore was chosen as it had unique design and high suitability for Photovoltaic (PV) installation. PGSHS is developed and organized by Punjab Government servants housing foundation (PGSHF). PGSHF allots houses to Government of Punjab's employees. The Study area is shown in Figure 1.

This study area is located at 31.400 north latitude, 74.170 East longitude and total area of society is 524,692 $\mathrm{m}^{2}$. PGSHS has high potential for solar energy generation as climate of Lahore is warm city so study area has a high amount of irradiance. Temperature range of PGSHS ranges between $30.8^{\circ} \mathrm{C}$ averages high to $17.8^{\circ} \mathrm{C}$ average low (source: NOAA (1961-1990)). In 2010, 738 millimeters rain fall was recorded. PGSHS pertain least topographic variation and suitable for PV installation. Nearly all the roofs possess same height as well as same elevation. There are four classes of houses at study area. The classes, number of houses and their areas are as shown in Table 1.

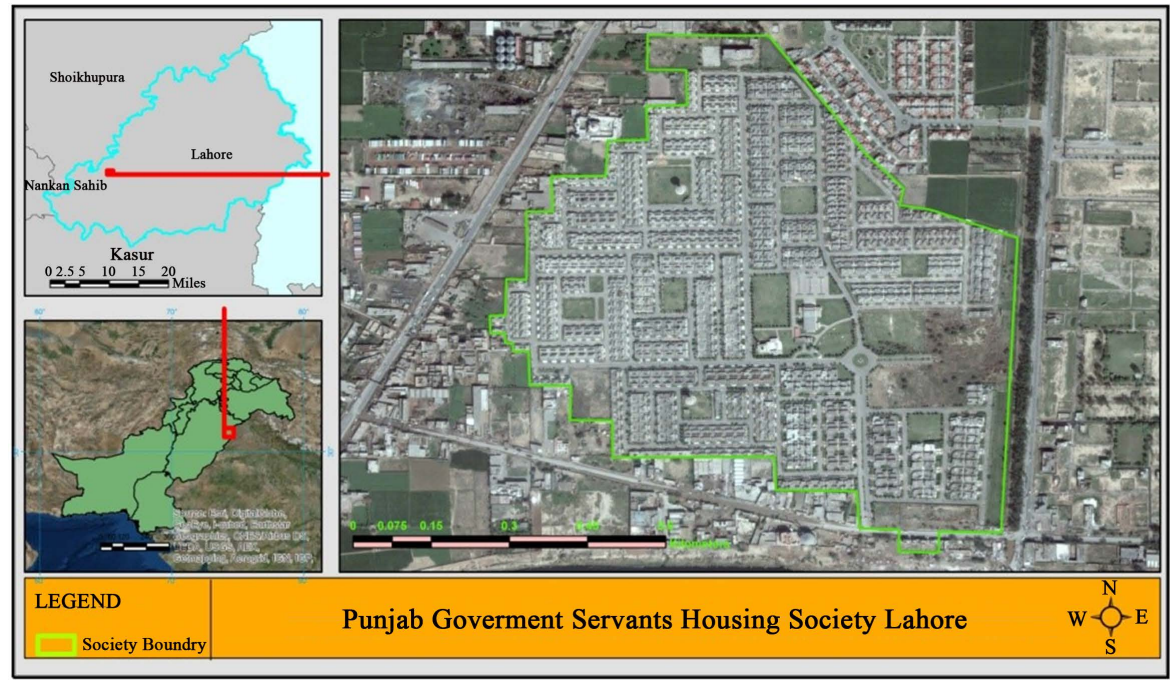

Figure 1. Study area.

Table 1. Study area buildings and types.

\begin{tabular}{cc} 
House Size & Number of Houses \\
\hline 5-Marla $\left(126.47 \mathrm{M}^{2}\right)$ & 598 \\
7-Marla $\left(177.05 \mathrm{M}^{2}\right)$ & 334 \\
10-Marla $\left(252.93 \mathrm{M}^{2}\right)$ & 304 \\
1 -Kanal $\left(505.86 \mathrm{M}^{2}\right)$ & 107 \\
\hline
\end{tabular}




\subsection{Database Development and Digitization}

Spatial data was prepared with the help of scanned maps provided by the PGSHS, satellite imagery and ground surveys while attribute information for the buildings and electricity bills was obtained by the PGSHS scanned maps, residences and Lahore Electric Supply Company's website. Seven layers were created for database. These layers consist of boundary of society, parcels, selected area, owner information, years, and month and raster layer for the calculation of solar energy potential as shown in Figure 2. For each layers attributes for added as fields and these layers were linked to each other by using a primary key. In GIS environment there is a two type of data; spatial as well as attribute data. Spatial data consist of parcels, roads, geometry, and proposed area for solar panel installation while attribute data consist of house number, their sizes, class, land use, potential etc. Figure 3 depicts flow chart for layers generation and their relationship in database. All stages from data collection to analysis and output are shown.

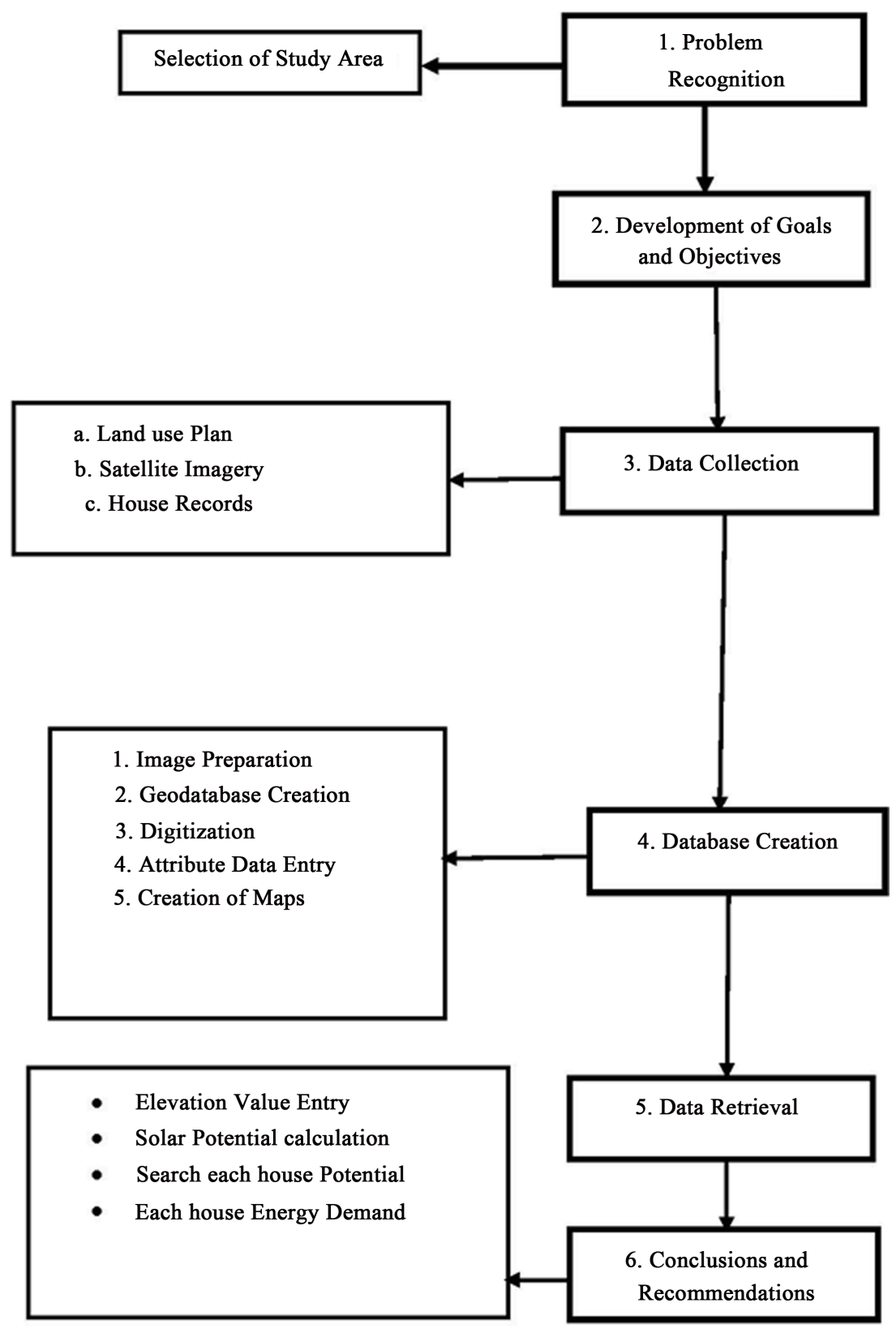

Figure 2. Flow chart of current study. 


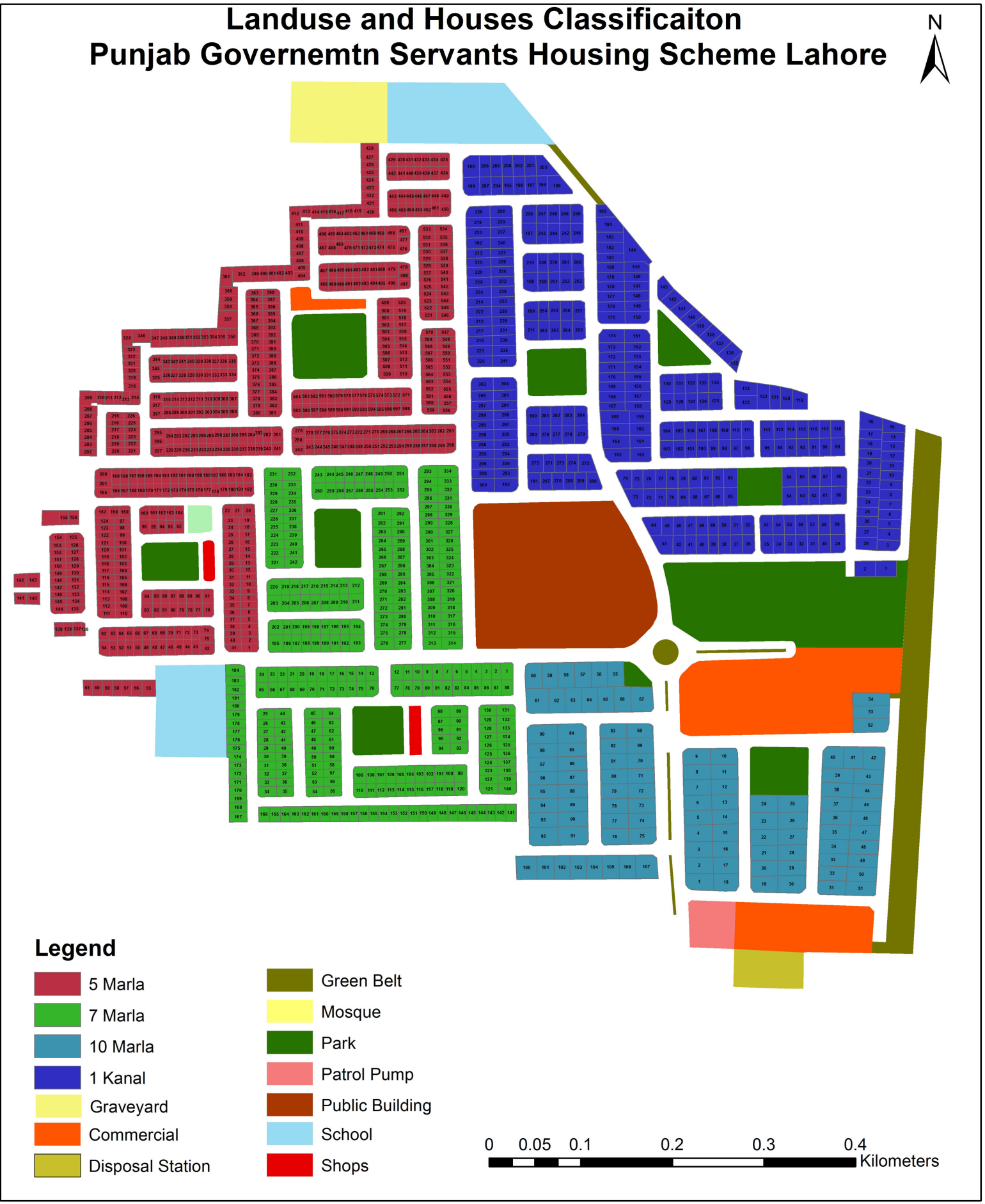

Figure 3. Classification of study area.

Google Earth imagery which provides free high resolutions satellite imagery visualization is utilized for digitization of rooftops in the study area. Imagery of the study area was downloaded by using Google Earth Pro software. March 18, 2014 was the latest image available there was Zero cloud cover in the imagery which makes it best for visual interpretation and digitization. This downloaded image was georefred according to coordinates of Google earth in Geographic coordinates system. The coordinate system was World Geodetic System 1984 
(WGS). Environmental Systems Research Institute's (ESRI) ArcGIS 10.1 software was used to georef this downloaded image.

Figure 4 depicts tables for Geodatabase. Their relationship was join with each other. Only three tables are geometry information; these are boundary, selected area and parcels. These geometry tables were digitized in ArcGIS software. Parcels are showing building types, their size, and property unit number as shown in Figure 2. Google Earth satellite imagery was used as a base map to digitize area for PV installation at rooftops of PGSHS.

The zoom level for the digitization of polygons was 1:250 in the ArcGIS software. Screen shot of digitized rooftops is shown in Figure 5. Only a specific portion of rooftops is selected for PV installation while the remaining roof is free for domestic uses. As there are four classes of houses in the study area so every class have different size so same area was selected for each roof in each class. School buildings and Commercial buildings in the study area are also considered while digitization for PV installation. To overcome the shadow problem only the mounts of rooftop of buildings are digitized.

There are some limitation for the PV installation, PV installation is effected due to slope [21]-[24], aspect [21], Direct normal irradiance or solar potential [21] [22] [25] [26], proximity to roads [26], distance to transmission lines/power lines [23] [25], sand/ dust risk [24], environmentally sensitive areas [24] [26], weather conditions [26] and many other factors like dam sites, cultural areas flood areas etc. Due to these factors only those roofs were selected during digitization for PV installation which meets the following criteria:

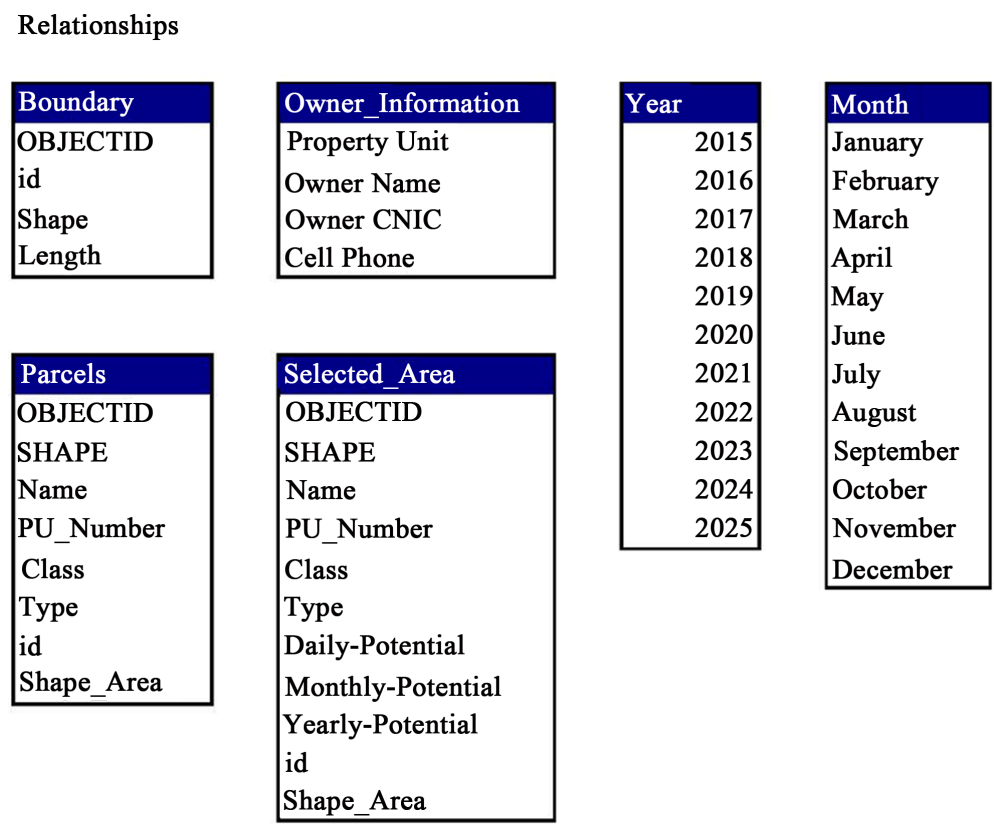

Figure 4. Creation of geodatabase.

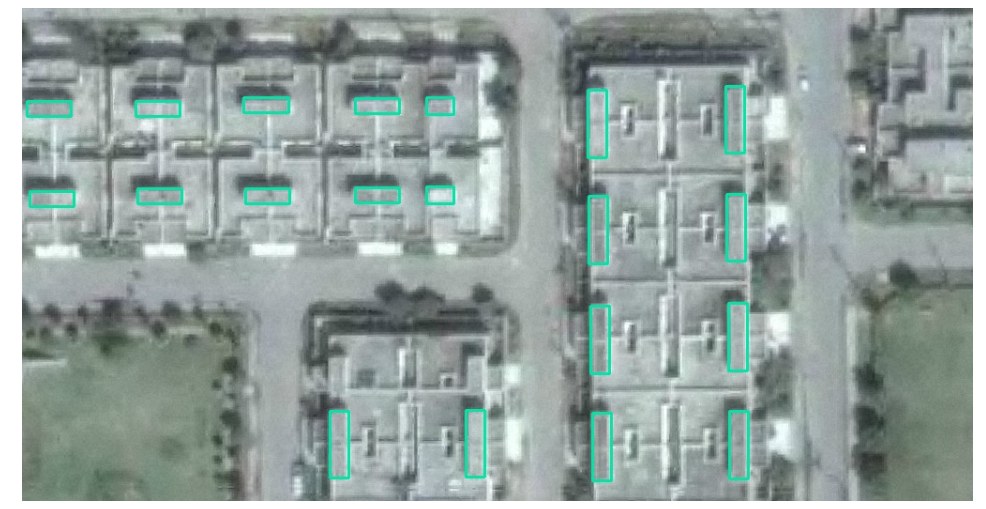

Figure 5. Sample set of rooftops. 
South, south east and south west directions are best for PV installation. All buildings in the study area have flat surfaces at the roofs, so orientation and slope are not hurdles for PV installation. There was lack of tilted roofs, shade free area was selected on the rooftops in this study. While digitization and selection best care is adopted to select the only roofs which receives direct solar radiations. Those rooftop areas which were shaded by other buildings, trees, structures or vegetation those may affect the solar yield were not included in the study. In the study area, there is unavailability of heating, ventilation, and air conditioning (HVAC) system so maximum roof is available for solar PV installation.

A Global Positioning Device (GPS) manufactured by the Garmin was used to know elevation in PGSHS. After averaged of eight points it was found that the elevation in the study area is 202 meter. Forty consumer bills were borrowed from the residence and scanned. It was found that there was a direct relation between the building size and utility bills. The Bigger the house the more the utility bill and vice versa. We collected bill for each class. GIS software is a convenient way to generate and develop maps of solar radiation potential and spatial relationship to other data (Fu and Rich, 1999). In present study, ESRI's software ArcGIS's tool is utilized for GIS modeling in study area to estimate solar radiation ns. The input for this tool for processing is a Raster dataset. This raster was converted from digitized roof polygons by using vector to raster conversion tool from toolbox of the software. These polygons were assigned average elevation values collected from the field by using GPS device. Electricity rate for all kind of consumers e.g. commercial as well as residential and bill data was download from Lahore Electric Supply Company (LESCO) website.

\section{Results}

By using solar flux tool in ArcGIS software it was found that average potential in the study are for generation of electric power was $1448 \mathrm{kWh} / \mathrm{m}^{2} /$ year for the year of 2014 . We considered that all the roof have same slope and elevation so all the roofs would produce same amount of energy as topography of study area is plan and Lahore is a plan city. By using the same software potential for each house was calculated for the time span of yearly, monthly and daily basis as shown in Figure 6.

For management purpose area of each house was calculated in ArcGIS software. Similarly area for PV installation for each house was calculated. The software have complete record for each house whether there is a difference of even one meter of a building to another building in tabular data as well as spatial data or geographically.

The information in Table 2 was summarized for the database of the study area. The record of each house, its area selected for PV installation its monthly, yearly electric energy generation is shown in Figure 7.

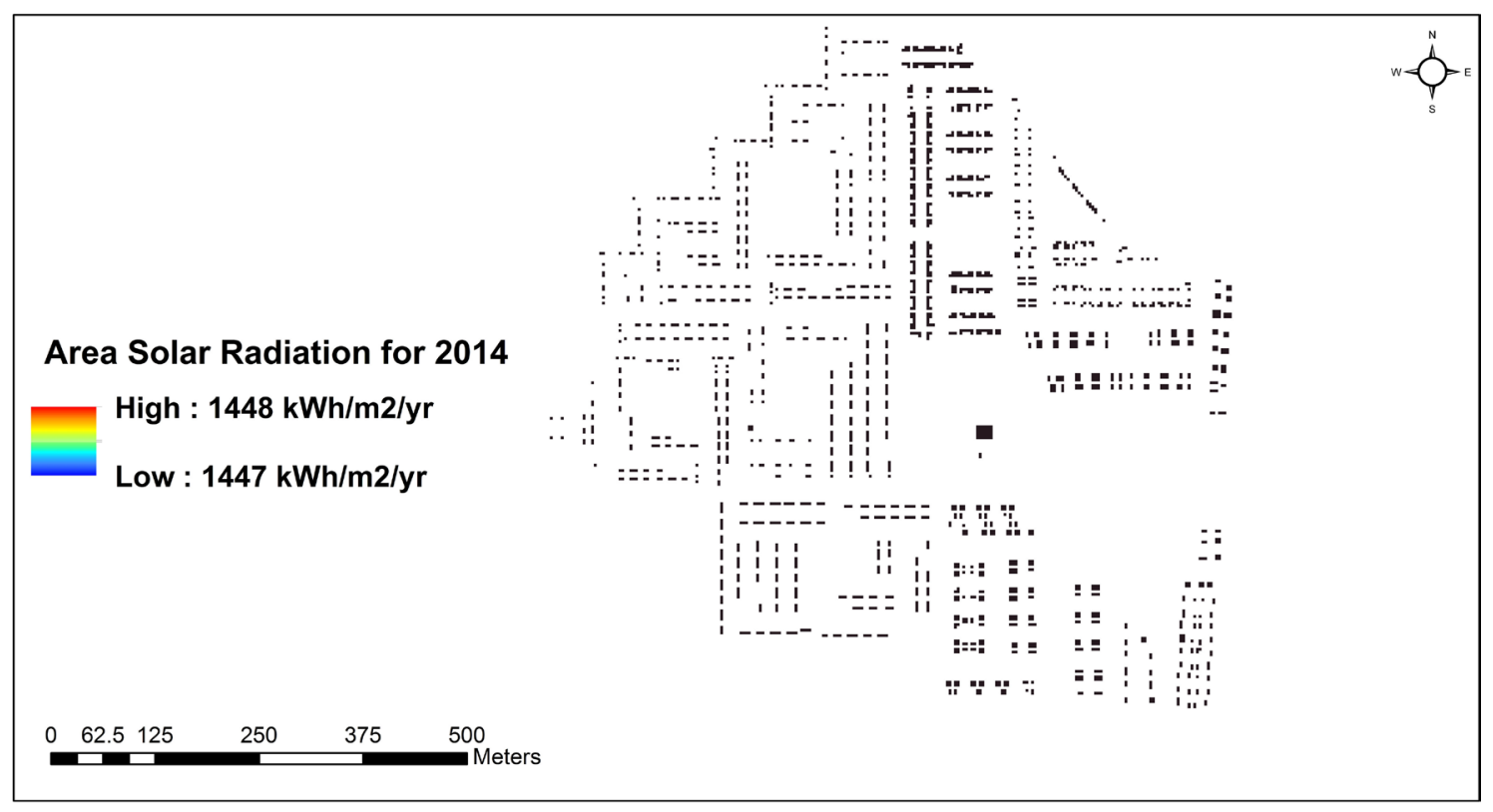

Figure 6. Annual solar radiation calculated for 2014. 
The Database can serve equal to any other database softwares. Any kind of information regarding house or solar panel would be added. Payments records, problem record, contact numbers etc. are example for the management. A separate database file containing information regarding house is shown in Figure 8. This file is joined spatially with the primary key of house unit number. The table can also be related to common field as a relationship. Meanwhile a number of separate table or field in same SQL attribute table would be added for monthly record for each coming years.

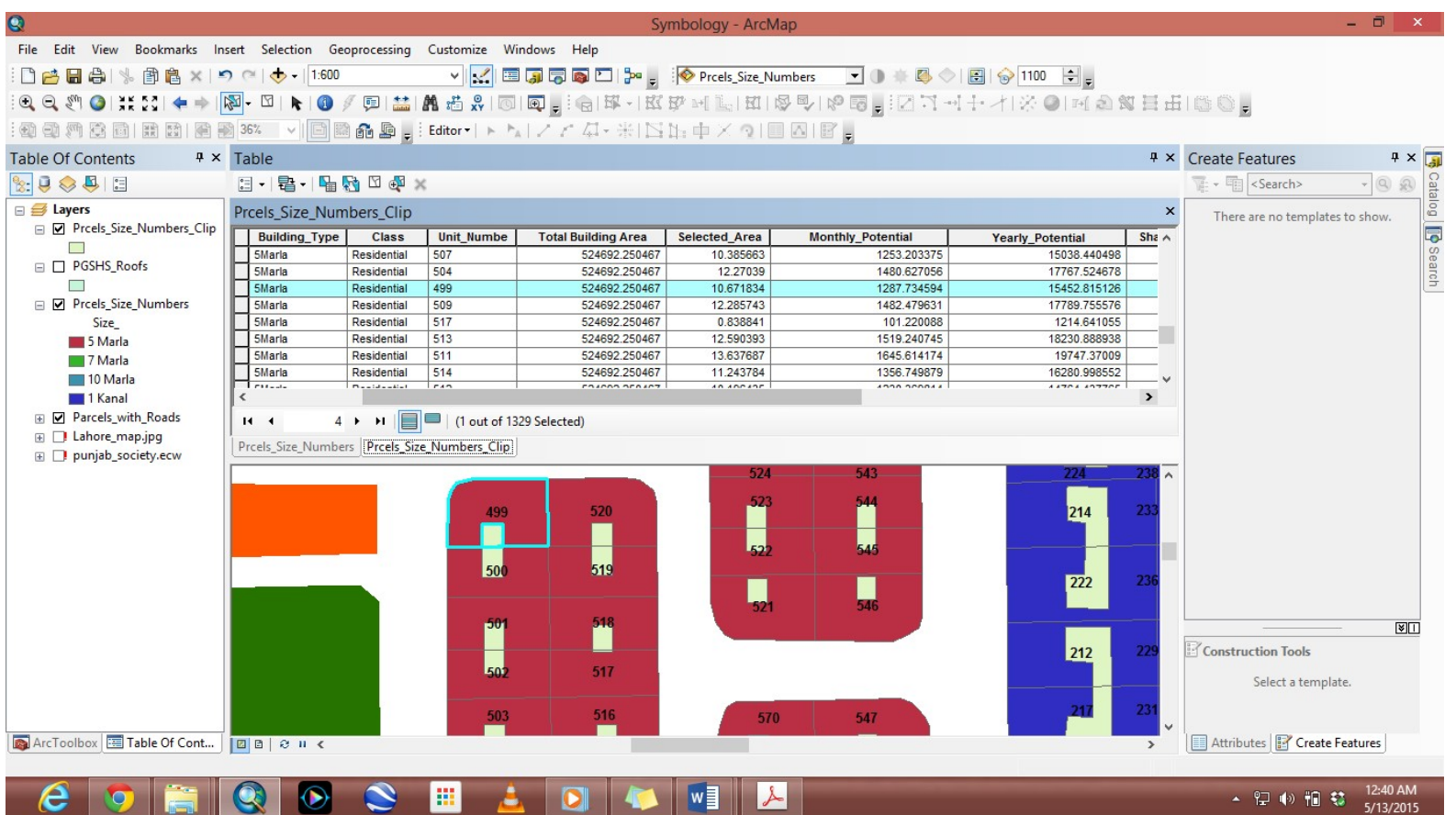

Figure 7. Spatial and tabular data depiction.

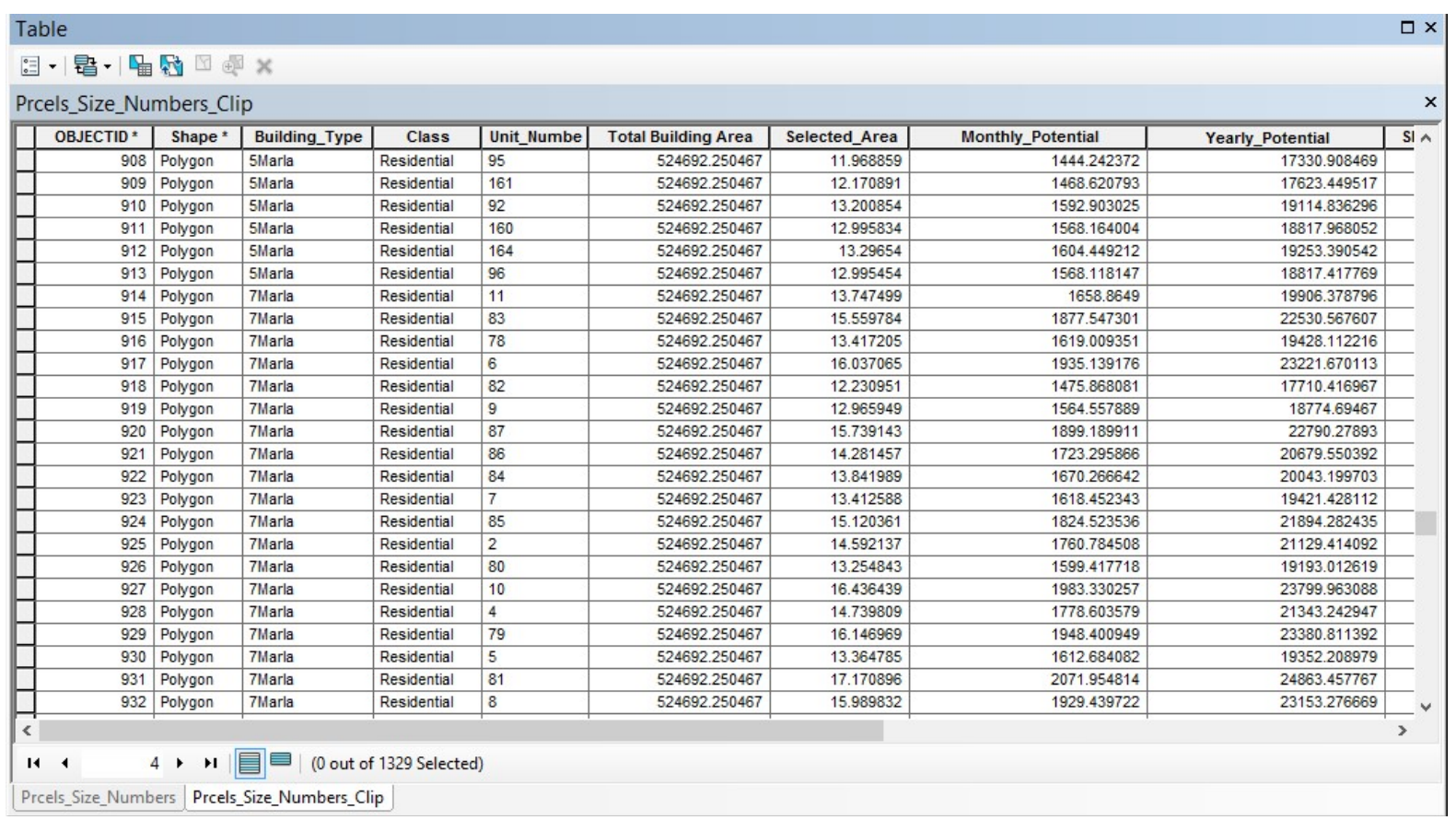

Figure 8. Detailed tabular data of parcels. 
Table 2. Suitable rooftop area by general building type.

\begin{tabular}{ccccc}
\hline Sr. \# & House Size & $\begin{array}{c}\text { Average Digitized } \\
\text { Roof Area } \text { m }^{2} \text { Per Building }\end{array}$ & $\begin{array}{c}\text { Total Digitized Roof } \\
\text { Area } \text { m }^{2} \text { All Buildings }\end{array}$ & Percentage of Total Area \\
\hline 1 & 19 & 6674 & $1.27 \%$ \\
2 & 5-Marla $\left(126.47 \mathrm{M}^{2}\right)$ & 29 & 5089 & $0.97 \%$ \\
3 & 7-Marla $\left(177.05 \mathrm{M}^{2}\right)$ & 31 & 4860 & $0.93 \%$ \\
4 & 10-Marla $\left(252.93 \mathrm{M}^{2}\right)$ & 37 & 10,212 & $1.94 \%$ \\
5 & 1-Kanal $\left(505.86 \mathrm{M}^{2}\right)$ & 60 & 541 & $0.10 \%$ \\
\end{tabular}

\section{Conclusion}

This study suggests that management and administrative process at a geographical area are so easy to manage using the geographic information system. The position of any object can easily be marked in GIS. This will be very helpful for maintenance work as location and direction of each building are available. This kind of application could be applied in any human resources organization.

\section{References}

[1] LeBoeuf, E.J., Dobbins, J.P. and Abkowitz, M.D. (2003) Development of a GIS-Based Spill Management Information System. Phase I: Proof of Principle Approach for the Cheatham Reach, Vanderbilt University. Civil and Environmental Engineering, Nashville.

[2] Dobbins, J.P. and Abkowitz, M.D. (2002) Development of an Inland Marine Transportation Risk Management Information System. > Transportation Research Record: Journal of the Transportation Research Board, 1782, 31. http://dx.doi.org/10.3141/1782-04

[3] Tsanis, I.K. and Boyle, S. (2001) A 2D Hydrodynamic/Pollutant Transport GIS Model. Advances in Engineering Software, 32, 353-361. http://dx.doi.org/10.1016/S0965-9978(00)00098-3

[4] Li, J. (2001) A GIS Planning Model for Urban Oil Spill Management. Water Science \& Technology, 43, $239-244$.

[5] Marsili-Libelli, S., Caporali, E., Arrighi, S. and Becattelli, C. (2001) A Georeferenced River Quality Model. Water Science \& Technology, 43, 223-230.

[6] Chen, Z., Huang, G.H. and Li, J.B. (2002) A GIS-Based Modeling System for Petroleum Waste Management. Water Science \& Technology, 47, 309-317.

[7] Goodchild, M.F. (1993) GIS and Environmental Modeling. Oxford University Press, New York, 58-75.

[8] Herberich, J. (2004) Integrated Data Management (Part II). Geographic Information Systems USGS. ENSR's Water Resources Department.

[9] Ahmad, S.R. and Lakhan, V.C. (2012) GIS-Based Analysis and Modeling of Coastline Advance and Retreat along the Coast of Guyana. Marine Geodesy, 35, 1-15. http://dx.doi.org/10.1080/01490419.2011.637851

[10] Sinnakaudan, S., Ahmad, M.S.S. and Mohamad, G. (2001) Development of Water Utility Management System Using GIS. Proceedings of Annual Seminar on Geoinformation, Penang, 12-13 November 2001.

[11] Sinnakaudan, S., Abubakar, S.H. and Nyuin, J.D. (2004) Development of the UiTM Campus Facility Information Management System (GeoCampus). Proceedings of the International Symposium on Geoinformation, Kuala Lumpur, 2123 September 2004, 384-386.

[12] Partheeban, P., Elangovan, C., Arulkumaran, M. and Hemamalini, R. (2003) Utility Management System for an Engineering College Using GIS Shri Angalamman College of Engineering and Technology. SACET, India.

[13] Ndukwe, N.K. (1997) Principles of Environmental Remote Sensing and Photo Interpretation. New Concept Publishers, Nigeria.

[14] ESRI (1990) Understanding GIS-The Arc/Info Method. A Workbook on Geographical ESRI, Redlands.

[15] PEPCO (2012) View Power Situations.

[16] Arifeen, M. (2013) Can Pakistan Meet Its Energy Needs? The Nation, 7.

[17] Khalil, M.S. (n.d.) Renewable Energy in Pakistan: Status and Trends. Pakistan Alternative Energy Development Board, Prime Minister's Secretariat. 
[18] Johnson, G. and Armanino, D. (2004) GIS Tools for Community Development Applications. Proceedings of the American Solar Energy Society (ASES) Solar Power 2004 Conference, San Francisco.

[19] Punjab, G. (2012) Power Projects in Punjab as on July. http://energy.punjab.gov.pk/power projects.html

[20] AEDB (n.d.) Alternative Energy Development Board, Resource Potential of Solar Photovoltaic.

[21] Bravo, J.D., Casals, X.G. and Pascua, I.P. (2007) GIS Approach to the Definition of Capacity and Generation Ceilings of Renewable Energy Technologies. Energy Policy, 35, 4879-4892. http://dx.doi.org/10.1016/i.enpol.2007.04.025

[22] Pletka, R., Block, S., Cummer, K., Gilton, K., R., O., Roush, B., Stoddard, L., Tilley, S., Woodward, D. and Hunsaker, M. (2007) Arizona Renewable Energy Assessment. Black \& Veatch Corporation, Overland Park.

[23] Broesamle, H., Mannstein, H., Schillings, C. and Trieb, F. (2001) Assessment of Solar Electricity Potentials in North Africa Based on Satellite Data and a Geographic Information System. Solar Energy, 70, 1-12. http://dx.doi.org/10.1016/S0038-092X(00)00126-2

[24] Charabi, Y. and Gastli, A. (2011) PV Site Suitability in Oman Analysis Using GIS-Based Spatial Fuzzy Multi-Criteria Evaluation. Renewable Energy, 36, 2554-2561. http://dx.doi.org/10.1016/j.renene.2010.10.037

[25] Fluri, T.P. (2009) The Potential of Concentrating Solar Power in South Africa. Energy Policy, 37, 5075-5080. http://dx.doi.org/10.1016/j.enpol.2009.07.017

[26] Dawson, L. and Schlyter, P. (2012) Less Is More: Strategic Scale Site Suitability for Concentrated Solar Thermal Power in Western Australia. Energy Policy, 47, 91-101. http://dx.doi.org/10.1016/j.enpol.2012.04.025 